УДК $634.8: 631.52$

DOI 10.30679/2219-5335-2021-5-71-171-180

МОДИФИКАЦИОНЫЕ
ИЗМЕНЕНИЯ ФЕНОТИПА
У ВИНОГРАДА ВЫДВИЖЕНЕЦ
ПОД ВЛИЯНИЕМ
ПРИРОДНЫХ УСЛОВИЙ
НА ФОНЕ ТРАДИЦИОННОГО
И БИОЛОГИЧЕСКИХ
СПОСОБОВ
СОДЕРЖАНИЯ ПОЧВЫ

Петров Валерий Семенович

д-р с.-х. наук

ведущий научный сотрудник

лаборатории управления

воспроизводством

в ампелоценозах и экосистемах

e-mail: Petrov_53@mail.ru

Федеральное государственное

бюджетное научное учреждение

«Северо-Кавказский федеральный научный иентр садоводства, виноградарства, виноделия», Краснодар, Россия

Установлены модификационые изменения фенотипа и норма реакции у технического сорта винограда Выдвиженец под влиянием природных условий на фоне традиционного и биологических способов содержания почвы. Исследования выполнены в агроэкологических условиях умеренно континентального климата юга России с использованием современных методов полевых исследований. Среднегодовая температура воздуха на участке исследований была $9,7^{\circ} \mathrm{C}$. Во время вегетации (май - сентябрь) температура была $19,9^{\circ} \mathrm{C}$, в период активного роста ягод винограда (II. июнь-III. август) $22,5^{\circ} \mathrm{C}$, максимальная поднималась до плюс $39,3^{\circ} \mathrm{C}$, минимальная в период зимовки винограда опускалась до минус $26,7^{\circ} \mathrm{C}$. Годовая амплитуда температур была $54,2^{\circ} \mathrm{C}$. Перепад температуры воздуха внутри дня в период
UDC $634.8: 631.52$

DOI 10.30679/2219-5335-2021-5-71-171-180

\section{MODIFICATION CHANGES IN THE PHENOTYPE OF VYDVIZHENEC GRAPE VARIETY UNDER THE INFLUENCE OF NATURAL CONDITIONS ON THE BACKGROUND OF TRADITIONAL AND BIOLOGICAL WAYS OF SOIL MANAGMENT}

Petrov Valeriy Semionovich Dr. Sci. Agr. Leading Research Associate of Reproduction Control in the Ampelocenoses and Ecological Systems Laboratory e-mail: Petrov_53@mail.ru

Federal State Budget

Scientific Institution

«North Caucasian Federal

Scientific Center of Horticulture, Viticulture, Wine-making», Krasnodar, Russia

Modification changes in the phenotype and the norm of reaction in the technical grape variety Vydvizhenec under the influence of natural conditions against the background of traditional and biological ways of soil management have been established. The studies were carried out in the agro-ecological conditions of the moderate continental climate of the south of Russia using modern methods of field research. The average annual air temperature at the research site was $9.7{ }^{\circ} \mathrm{C}$. During the growing season (May-September) the temperature was $19.9^{\circ} \mathrm{C}$, during the period of active growth of grape berries (II. June-III. August) $22.5^{\circ} \mathrm{C}$, the maximum rose to plus $39.3^{\circ} \mathrm{C}$, the minimum in the wintering period of grapes dropped to minus $26.7^{\circ} \mathrm{C}$. The annual temperature range was $54.2^{\circ} \mathrm{C}$. The drop in air temperature within the day during the growing season was 
вегетации был 10,7 градусов по Цельсию, максимальный $-17,7^{\circ} \mathrm{C}$. Годовая сумма атмосферных осадков менялась от 433 до 866 мм, при норме 620 мм.

Варьирование погодных условий сопровождалось модификационной изменчивостью количества гроздей, средней массы грозди и урожая винограда. По данным корреляционного анализа наиболее сильное влияние оказывали минимальная температура воздуха (январь - февраль) на количество гроздей $(\mathrm{r}=0,64-0,41)$ и среднюю массу грозди $(\mathrm{r}=-0,67--0,52)$, средняя температура в предшествующий год на количество гроздей $(\mathrm{r}=0,65-0,41)$, средняя годовая температура на массу грозди $(\mathrm{r}=-0,47--0,35)$. Атмосферные осадки в целом за год оказывали влияние на массу грозди $(\mathrm{r}=-0,38--0,30)$.

Влияние погодных условий на урожай винограда было слабым. Норма реакции количества гроздей была равна на фоне черного пара 23, естественного задернения 25 и посева щавеля кислого 30 шт./куст, средней массы грозди соответственно 129, 90 и 103 г, урожая винограда 5,79; 5,52 и 6,00 кг/куст.

Ключевые слова: ВИНОГРАД, СРЕДА ОБИТАНИЯ, ФЕНОТИП, МОДИФИКАЦИОННАЯ ИЗМЕНЧИВОСТЬ, НОРМА РЕАКЦИИ
10.7 degrees Celsius, the maximum $17.7^{\circ} \mathrm{C}$. The annual amount of atmospheric precipitation varied from 433 to $866 \mathrm{~mm}$, with a norm of $620 \mathrm{~mm}$. Variations in weather conditions were accompanied by modification variability in the number of clusters, average cluster weight, and grape yield. According to the correlation analysis, the strongest influence was exerted by the minimum air temperature (January-February) on the number of clusters $(r=0.64 \ldots 0.41)$ and the average cluster mass $(r=-0.67 \ldots-0.52)$, the average temperature in the previous year by the number of clusters $(r=0.65 \ldots 0.41)$, the average annual temperature per cluster weight $(r=-0.47 \ldots-0.35)$. Atmospheric precipitation as a whole for the year influenced the mass of the cluster $(r=-0.38 \ldots-0.30)$. The influence of weather conditions on the grape yield was weak. The reaction norm of the number of clusters was equal 23 against the background of black fallow, 25 - natural grassing-down and $30 \mathrm{pcs} / \mathrm{bush}$ - sowing of sour dock, the average weight of the cluster, respectively, 129,90 and $103 \mathrm{~g}$, the grape yield - 5.79; 5,52 and $6,00 \mathrm{~kg} / \mathrm{bush}$.

Key words: GRAPES, AMBIENT, PHENOTYPE, MODIFICATION VARIABILITY, NORM OF REACTION

Введение. Российское промышленное виноградарство сосредоточено в Северо-Кавказском и Южном федеральном округах в условиях умеренноконтинентального климата. Для такого климата характерными являются нестабильные погодные условия - годовые, сезонные, суточные перепады температур воздуха до критических, острый дефицит атмосферных осадков [1-3]. Виноградное растение, обладая высокой адаптивной пластичностью, адекватно реагирует модификационной изменчивостью фенотипических признаков на изменение абиотических и антропогенных факторов [4-9]. Этот биологический признак позволяет растению произрастать и эффективно 
плодоносить в нестабильных условиях среды обитания, переносить высокие максимальные и низкие минимальные температуры воздуха [10-15].

Модификационная изменчивость может варьировать в широком диапазоне и выражается нормой реакции. Параметры нормы реакции растений, выраженные показателями количества гроздей и их массы, а также продуктивностью винограда, имеют большое научное и практическое значение для создания новых сортов и выработки сорториентированных агротехнологий функционально направленного выращивания винограда [16-20].

Цель настоящих исследований - установить пределы модификационной изменчивости фенотипических признаков - количества и массы грозди, урожая винограда технического сорта Выдвиженец в агроэкологических условиях юга России. Данные исследования выполнены впервые.

Объекты и методы исследований. В качестве объекта исследований использовали широко распространенный в промышленном производстве технический сорт винограда Выдвиженец. Предмет исследований - модификационые изменения фенотипических признаков - количество и масса гроздей, урожай винограда под влиянием природных условий на фоне традиционного (черный пар) и биологических способов содержания почвы (задернение междурядий естественно отрастающими травами, преимущественно злаковыми и сеяными - щавелем кислым (Rúmex acetósa)).

Исследования выполнены в агроэкологических условиях умеренно континентального климата юга России на обыкновенных черноземах с использованием современных методов полевых исследований [21].

обсуждение результатов. Среднегодовая температура воздуха на опытном участке в период исследований была $9,7^{\circ} \mathrm{C}$, во время вегетации (май-сентябрь) - $19,9^{\circ} \mathrm{C}$, в период активного роста ягод винограда (ІІ.июньIII.август) - $22,5^{\circ} \mathrm{C}$, максимальная поднималась до плюс $39,3{ }^{\circ} \mathrm{C}$, минимальная в период зимовки винограда опускалась до минус $26,7^{\circ} \mathrm{C}$. Амплитуда 
температур воздуха в период исследований обладала широким диапазоном по сезонам года, а также сильно менялась внутри суток. Годовая амплитуда температур воздуха достигала в среднем $54,2{ }^{\circ} \mathrm{C}$, наибольшая была $60,3{ }^{\circ} \mathrm{C}$, наименьшая $-48,9^{\circ} \mathrm{C}$. Перепад температур внутри дня в период вегетации был в среднем за годы исследований 10,7 градусов по Цельсию, максимальный $-17,7^{\circ} \mathrm{C}$. Годовая сумма атмосферных осадков менялась в диапазоне от 433 до 866 мм, при норме 620 мм. В период вегетации винограда атмосферные осадки варьировали от 131 до 487 мм, при норме 286 мм, во время активного роста ягод винограда соответственно от 58 до 341 при норме 148 мм. Таким образом, онтогенез растений винограда на участке исследований проходил в нестабильных погодных условиях умеренно континентального климата.

Нестабильные погодные условия сопровождались модификационной изменчивостью фенотипических признаков винограда. Парный корреляционный анализ показал, что на модификационную изменчивость винограда Выдвиженец оказывали влияние минимальная температура воздуха (январь - февраль), средняя температура за год и вегетацию (май-сентябрь), а также во время активного роста ягод (II июнь - III август), атмосферные осадки в целом за год. Наиболее сильное влияние оказывали: минимальная температура воздуха на количество гроздей $(\mathrm{r}=0,64-0,41)$ и среднюю массу грозди $(\mathrm{r}=-0,67--0,52)$; средняя температура в предшествующий год на количество гроздей $(\mathrm{r}=0,65-0,41)$; средняя годовая температура на массу грозди $(\mathrm{r}=-0,47--0,35)$. Атмосферные осадки в целом за год оказывали влияние на массу грозди ( $\mathrm{r}=-0,38--0,30)$ (табл.).

Модификационная изменчивость фенотипических признаков - количества гроздей, средней массы грозди и урожая винограда под влиянием варьирования погодных условий была неоднозначной.

Нижний порог модификационной изменчивости количества гроздей на фоне черного пара был равен 18 шт./куст, естественного задернения 17 шт./куст и посева щавеля кислого 17 шт./куст, верхний соответственно 
Плодоводство и виноградарство Юга России № 71(5), 2021 г.

41, 42 и 47 шт./куст. Норма реакции была равна на фоне черного пара 23, естественного задернения 25 и посева щавеля кислого 30 шт./куст (рис. 1).

Нижний порог модификационной изменчивости средней массы грозди на фоне черного пара, естественного задернения и посева щавеля кислого был равен соответственно 106, 103 и 114, верхний 235, 193 и 217 г. Норма реакции соответствовала 129, 90 и 103 г (рис. 2).

Корреляционная зависимость фенотипических признаков винограда Выдвиженец от погодных условий на фоне традиционного и биологических способов содержания почвы

\begin{tabular}{|c|c|c|c|c|c|c|c|}
\hline \multirow{2}{*}{ 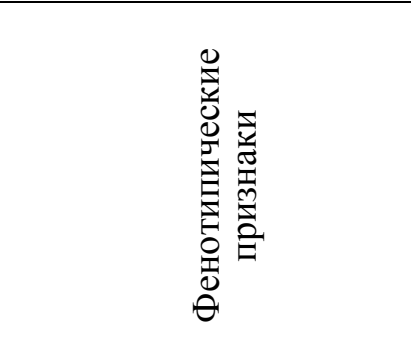 } & \multicolumn{3}{|c|}{$\begin{array}{c}\text { Температура воздуха } \\
\text { средняя }\end{array}$} & \multirow{2}{*}{ 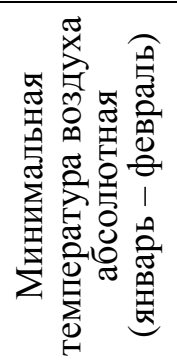 } & \multicolumn{3}{|c|}{$\begin{array}{c}\text { Атмосферные осадки, } \\
\text { мм }\end{array}$} \\
\hline & 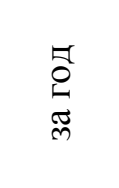 & 㺼 & 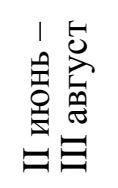 & & $\begin{array}{l}\text { F } \\
\text { 음 } \\
\text { త్ల }\end{array}$ & 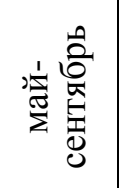 & 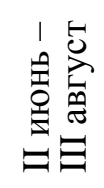 \\
\hline \multicolumn{8}{|c|}{ Черный пар } \\
\hline $\begin{array}{l}\text { Количество гроздей, } \\
\text { шт./куст* }\end{array}$ & 0,06 & $-0,06$ & 0,16 & 0,52 & 0,25 & 0,40 & 0,25 \\
\hline $\begin{array}{l}\text { Количество гроздей, } \\
\text { шт./куст** }\end{array}$ & 0,49 & 0,56 & 0,48 & - & $-0,08$ & $-0,25$ & $-0,21$ \\
\hline Средняя масса грозди, г & $-0,35$ & $-0,25$ & $-0,22$ & $-0,52$ & $-0,38$ & $-0,06$ & $-0,02$ \\
\hline Урожай, кг/куст & $-0,21$ & $-0,20$ & $-0,06$ & $-0,11$ & $-0,15$ & 0,16 & 0,11 \\
\hline \multicolumn{8}{|c|}{ Естественное задернение } \\
\hline $\begin{array}{l}\text { Количество гроздей, } \\
\text { шт./куст* }\end{array}$ & 0,20 & $-0,16$ & 0,08 & 0,41 & 0,13 & 0,31 & 0,23 \\
\hline $\begin{array}{l}\text { Количество гроздей, } \\
\text { шт./куст** }\end{array}$ & 0,43 & 0,53 & 0,41 & - & $-0,10$ & $-0,36$ & $-0,27$ \\
\hline Средняя масса грозди, г & $-0,47$ & $-0,17$ & $-0,21$ & $-0,56$ & $-0,38$ & $-0,05$ & $-0,08$ \\
\hline Урожай, кг/куст & $-0,13$ & $-0,17$ & $-0,04$ & $-0,09$ & $-0,14$ & 0,15 & 0,09 \\
\hline \multicolumn{8}{|c|}{ Щавель кислый } \\
\hline $\begin{array}{l}\text { Количество гроздей, } \\
\text { шт./куст* }\end{array}$ & 0,22 & $-0,26$ & $-0,05$ & 0,64 & 0,04 & 0,21 & 0,21 \\
\hline $\begin{array}{l}\text { Количество гроздей, } \\
\text { шт./куст** }\end{array}$ & 0,58 & 0,65 & 0,65 & - & $-0,05$ & $-0,43$ & $-0,32$ \\
\hline Средняя масса грозди, г & $-0,38$ & $-0,07$ & $-0,10$ & $-0,67$ & $-0,30$ & $-0,02$ & $-0,10$ \\
\hline Урожай, кг/куст & $-0,07$ & $-0,23$ & $-0,07$ & 0,08 & $-0,11$ & 0,19 & 0,13 \\
\hline
\end{tabular}

*Корреляционная зависимость количества гроздей от погодных условий текущего года

**Корреляционная зависимость количества гроздей от погодных условий предшествующего года 
Плодоводство и виноградарство Юга России № 71(5), 2021 г.

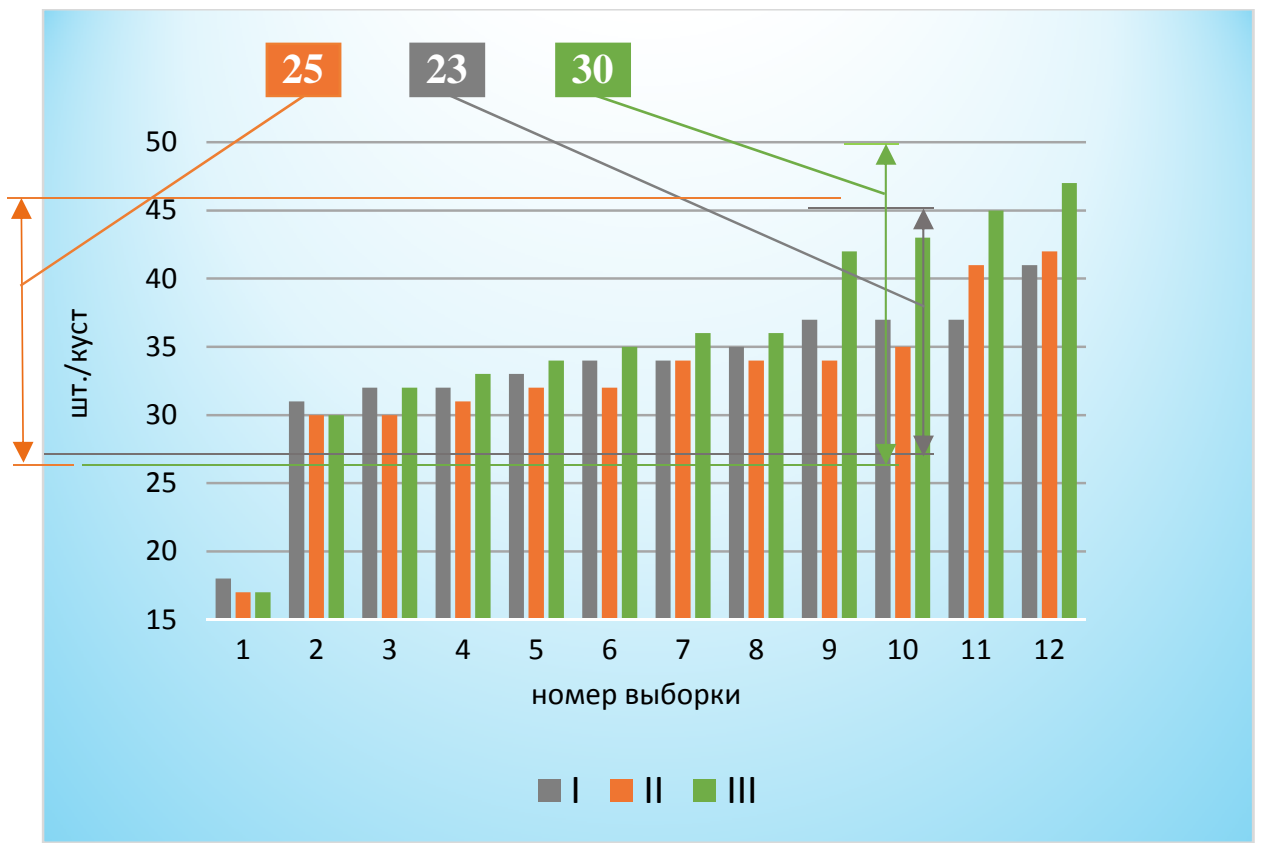

Рис. 1. Норма реакции винограда Выдвиженец по количеству гроздей с куста на природные условия среды обитания на фоне черного пара (I), естественного задернения (II) и посева щавеля кислого (III)

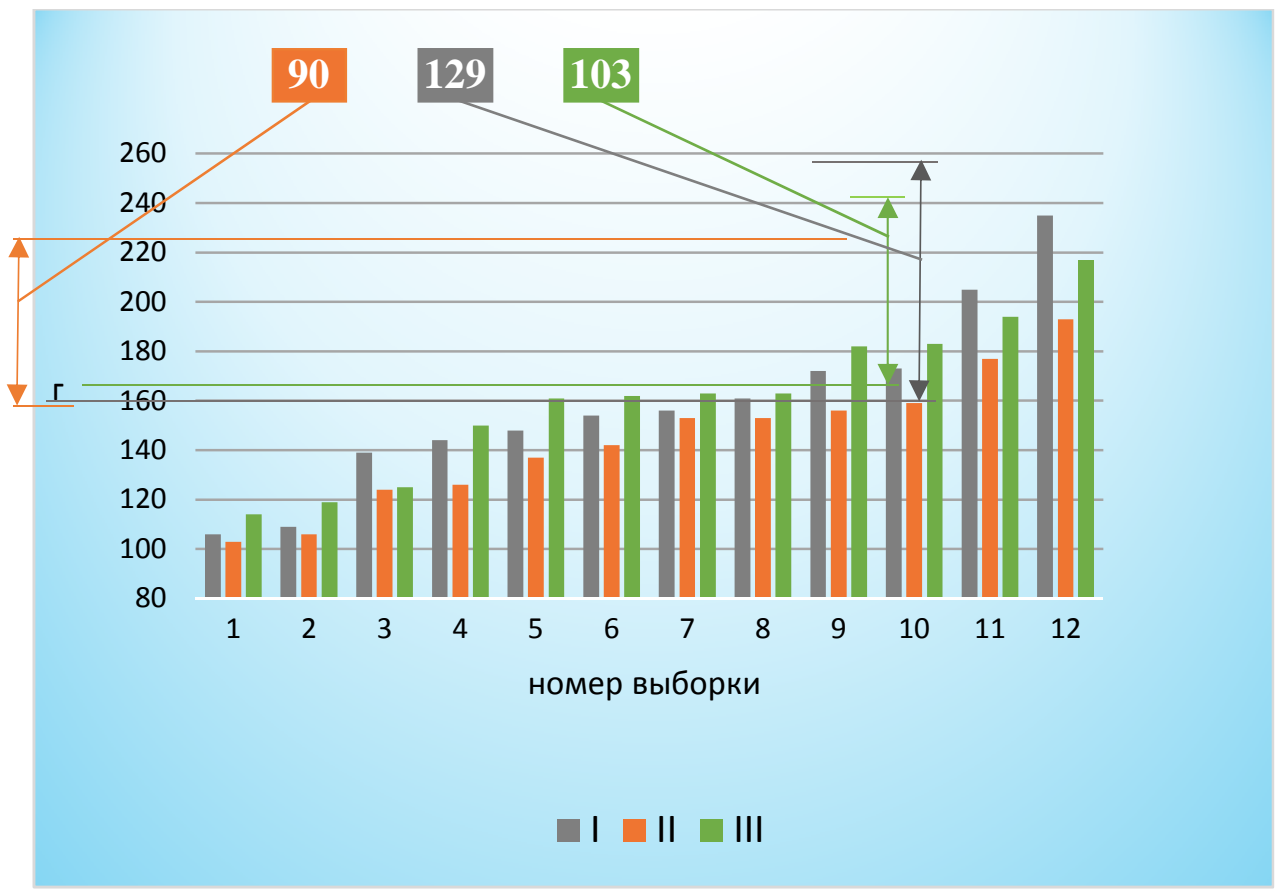

Рис. 2. Норма реакции винограда Выдвиженец по параметрам средней массы грозди на природные условия среды обитания на фоне черного пара (I), естественного задернения (II) и посева щавеля кислого (III)

Нижний порог модификационной изменчивости урожая винограда на фоне черного пара, естественного задернения и посева щавеля кислого был 
равен соответственно 2,9; 2,6 и 3,1, верхний 8,7; 8,1 и 9,1 кг/куст. Норма реакции соответствовала 5,79; 5,52 и 6,00 кг/куст (рис. 3).

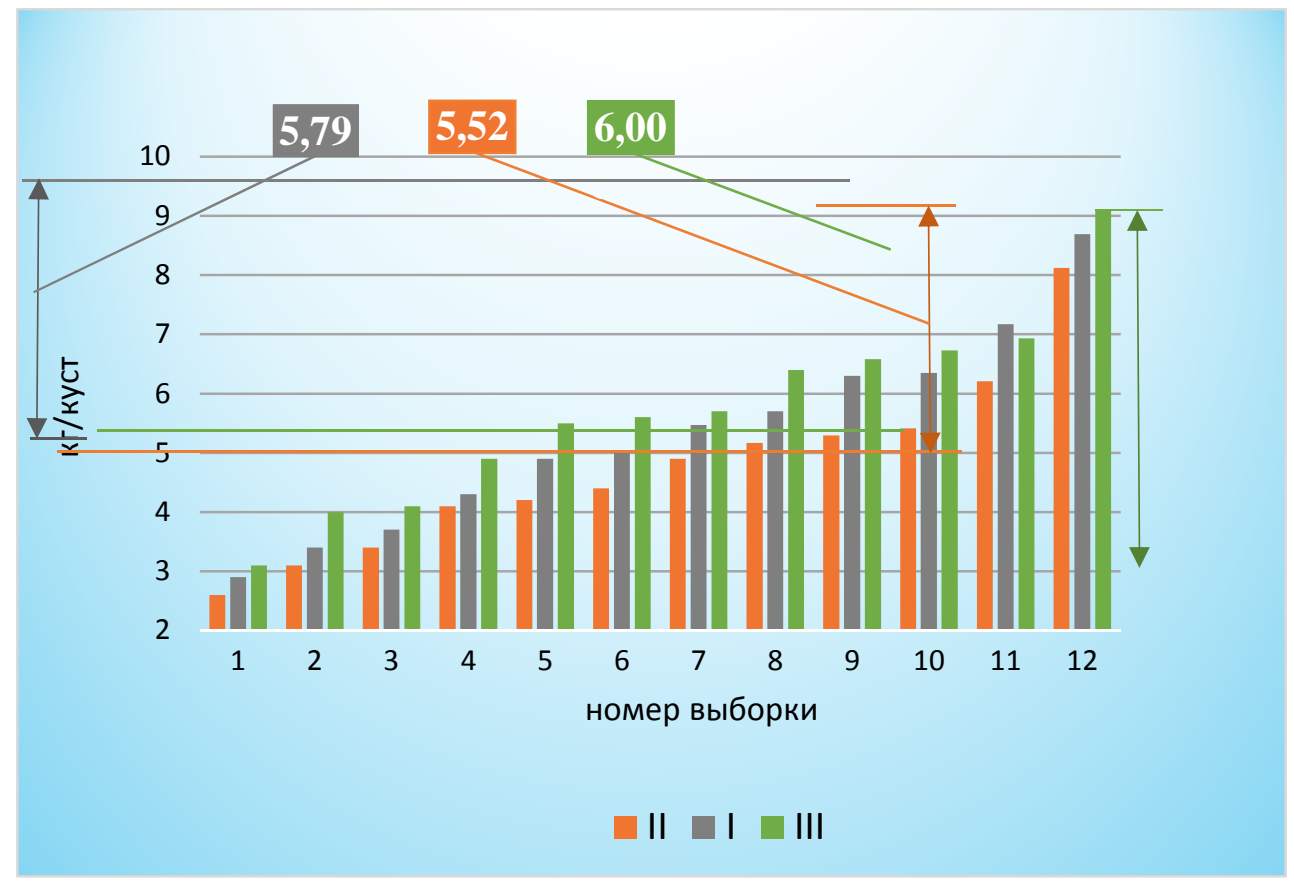

Рис. 3. Норма реакции винограда Выдвиженец по параметрам урожая на природные условия среды обитания на фоне черного пара (I), естественного задернения (II) и посева щавеля кислого (III)

Bbыводы. Установлено влияние варьирования погодных условий на модификационную изменчивость количества гроздей, средней массы грозди и урожая винограда технического сорта Выдвиженец. Наиболее сильное влияние оказывали: минимальная температура воздуха (январь - февраль) на количество гроздей $(\mathrm{r}=0,64-0,41)$ и среднюю массу грозди $(\mathrm{r}=-0,67-0,52)$; средняя температура в предшествующий год на количество гроздей $(\mathrm{r}=0,65-0,41)$; средняя годовая температура на массу грозди $(\mathrm{r}=-0,47--0,35)$. Атмосферные осадки в целом за год оказывали влияние на массу грозди ( $\mathrm{r}=-0,38--0,30)$. Влияние погодных условий на урожай винограда было слабым. Норма реакции количества гроздей была равна на фоне черного пара 23, естественного задернения 25 и посева щавеля кислого 30 шт./куст, средней массы грозди соответственно 129, 90 и 103 г, урожая винограда 5,79; 5,52 и 6,00 кг/куст. 


\section{Литература} 2020. 234 c.

1. Лукьянова Н.С. География: М.: Московский гуманитарный университет,

2. Петров В.С., Павлюкова Т.П., Талаш А.И. Научные основы устойчивого выращивания винограда в аномальных погодных условиях: монография / Под общ. ред. В.С. Петрова. Краснодар: ГНУ СКЗНИИСиВ, 2014. 157 с.

3. Система виноградарства Ставропольского края: монография / Е.А. Егоров [и др.]. Краснодар: ГНУ СКЗНИИСиВ, Союз виноградарей и виноделов Ставрополья, 2010. 156 c.

4. Bucur G.M., Dejeu L. Research on climate - grapevine yield relationship and the impact of global warming // Bull. Univ. Agr. Sci. and Vet. Met., Cluj-Napoca. Ser. Hort. 2014. Vol. 71(2). P. 339-340. http://dx.doi.org/10.15835/buasvmcn-hort:10402

5. Brunetto G., De Melo G.W.B., Toselli M., Quartieri M., Tagliavini M. The role of mineral nutrition on yields and fruit quality in grapevine, pear and apple // Rev. Bras. Frutic. 2015. Vol. 37 (4). P. 1089-1104. https://doi.org/10.1590/0100-2945-103/15

6. Perin C., Fait A., Palumbo F., Lucchin M., Vannozzi A. The Effect of Soil on the Biochemical Plasticity of Berry Skin in Two Italian Grapevine (V. vinifera L.) Cultivars // Front. Plant Sci. 2020. Vol. 11. 822. http://doi.org/10.3389/fpls.2020.00822

7. Руссо Д.Э., Красильников А.А. Шелудько О.Н. Влияние специальных органоминеральных микроудобрений нового поколения на качество винограда и виноматериалов [Электронный ресурс] // Плодоводство и виноградарство Юга России. 2021. № 67(1). C. 261-282. Режим доступа: http://doi.org/10.30679/2219-5335-2021-1-67-261-282 (дата обращения: 10.06.2021).

8. Pavlyuchenko N., Zimina N., Melnikova S., Kolesnikova O. Influence of the rootstock variety on the vegetative and uvological measures of grapes // E3S Web of Conferences. 2020. Vol. 210. $05011 \mathrm{https://doi.org/10.1051/e3sconf/202021005011}$

9. Marmorshtein A., Petrov V., Lukyanov A., Lukyanova A., Kovalenko A. Impact of the south Russia weather conditions on the fruitfulness coefficients of domestic breeding grape varieties. В сборнике: E3S Web of Conferences. Cep. «International Scientific and Practical Conference «Fundamental and Applied Research in Biology and Agriculture: Current Issues, Achievements and Innovations», FARBA 2021» 2021.

10. Popovic T., Mijovic S., Raicevic D., Pajovic R. Impact of climate factors on yield and quality of vine variety Cabernet Sauvignon in Podgorica wine growing region // Agriculture and Forestry. 2016. Vol. 62 (2). P. 275-282. http://dx.doi.org/10.17707/AgricultForest.62.2.24

11. Boselli M., Tempesta G., Fiorilo M., Brandi M. Resistance and resilience to changing climate of Tuscany and Valpolicella wine grape growing regions in Italy // BIO Web Conf. 2016. Vol. 7. 01012. https://doi.org/10.1051/bioconf/20160701012

12. Gavrilescu G., Bois B. Chardonnay wines climate plasticity: A worldwide geographical approach / Plasticité des vins issus de cépage Chardonnay au climat : une approche géographique à l'échelle planétaire // BIO Web Conf. 2016. Vol. 7. 01013. https://doi.org/10.1051/bioconf/20160701013

13. Lung M-L., Pop N., Ciobanu F., Babes A., Bunea C., Lazar S.-L. Environmental Factors Influence on Quality of Wine Grape Varieties in Four Different Areas of Culture // Bul. Univ. Agr. Sci. and Vet. Med. Cluj-Napoca. Hort. 2012. Vol. 69 (1). P. 219-227.

14. Кисиль М.Ф., Владов П.Г. Формирование продуктивного потенциала винограда в зависимости от экологических условий // Виноделие и виноградарство. 2010. № 1. C. 30-31.

15. Наумова Л.Г., Новикова Л.Ю. Анализ тенденций изменения урожайности сортов винограда коллекции ВНИИВиВ им. Я.И. Потапенко // Виноделие и виноградарство. 2014. № 5. С. 44-49. 
16. Koyama K., Ikeda H., Poudel P.R., Goto-Yamamoto N. Light quality affects flavonoid biosynthesis in young berries of Cabernet Sauvignon grape // Phytochemistry. 2012. Vol. 78. P. 54-64 (2012) http://doi.org/10.1016/j.phytochem.2012.02.026

17. Анапская ампелографическая коллекция (биологические растительные ресурсы) / Егоров Е.А., Ильина И.А., Петров В.С. [и др.]. Краснодар, 2018. 194 с.

18. Стратегия улучшения сортимента винограда для качественного виноделия / Петров В.С. [и др.] // Достижения, проблемы и перспективы развития отечественной виноградовинодельческой отрасли на современном этапе: материалы Международной науч.-практ. конф. Российская академия сельскохозяйственных наук, ФГБНУ Всероссийский научно-исследовательский институт виноградарства и виноделия имени Я.И. Потапенко Российской академии сельскохозяйственных наук (ГНУ ВНИИВиВ Россельхозакадемии). 2013. С. 113-119.

19. Terry D.B., Kurtural S.K. Achieving Vine Balance of Syrah with Mechanical Canopy Management and Regulated Deficit Irrigation // Am. J. Enol. Vitic. 2011. Vol. 62 (4). P. 426-437 http://doi.org/10.5344/ajev.2011.11022

20. Martinez Toda F., Balda P. Reducing the $\mathrm{pH}$ of wine by increasing grape sunlight exposure: a method to mitigate the effects of climate warming // Vitis. 2014. Vol. 53(1). P. 17-20. https://doi.org/10.5073/vitis.2014.53.17-20

21. Петров В.С., Алейникова Г.Ю., Марморштейн А.А. Агроэкологическое зонирование территории для оптимизации размещения сортов, устойчивого виноградарства и качественного виноделия: монография. Краснодар: ФГБНУ СКФНЦСВВ, 2020. 138 с.

\section{References}

1. Luk'yanova N.S. Geografiya: M.: Moskovskij gumanitarnyj universitet, 2020. 234 s.

2. Petrov V.S., Pavlyukova T.P., Talash A.I. Nauchnye osnovy ustojchivogo vyrashchivaniya vinograda $\mathrm{v}$ anomal'nyh pogodnyh usloviyah: monografiya / Pod obshch. red. V.S. Petrova. Krasnodar: GNU SKZNIISiV, 2014. 157 s.

3. Sistema vinogradarstva Stavropol'skogo kraya: monografiya / E.A. Egorov [i dr.]. Krasnodar: GNU SKZNIISiV, Soyuz vinogradarej i vinodelov Stavropol'ya, 2010. 156 s.

4. Bucur G.M., Dejeu L. Research on climate - grapevine yield relationship and the impact of global warming // Bull. Univ. Agr. Sci. and Vet. Met., Cluj-Napoca. Ser. Hort. 2014. Vol. 71(2). P. 339-340. http://dx.doi.org/10.15835/buasvmcn-hort:10402.

5. Brunetto G., De Melo G.W.B., Toselli M., Quartieri M., Tagliavini M. The role of mineral nutrition on yields and fruit quality in grapevine, pear and apple // Rev. Bras. Frutic. 2015. Vol. 37 (4). P. 1089-1104. https://doi.org/10.1590/0100-2945-103/15.

6. Perin C., Fait A., Palumbo F., Lucchin M., Vannozzi A. The Effect of Soil on the Biochemical Plasticity of Berry Skin in Two Italian Grapevine (V. vinifera L.) Cultivars // Front. Plant Sci. 2020. Vol. 11. 822. http://doi.org/10.3389/fpls.2020.00822.

7. Russo D.E., Krasil'nikov A.A. Shelud'ko O.N. Vliyanie special'nyh organomineral'nyh mikroudobrenij novogo pokoleniya na kachestvo vinograda i vinomaterialov [Elektronnyj resurs] // Plodovodstvo i vinogradarstvo Yuga Rossii. 2021. № 67(1). S. 261-282. Rezhim dostupa: http://doi.org/10.30679/2219-5335-2021-1-67-261-282 (data obrashcheniya: 10.06.2021).

8. Pavlyuchenko N., Zimina N., Melnikova S., Kolesnikova O. Influence of the rootstock variety on the vegetative and uvological measures of grapes // E3S Web of Conferences. 2020. Vol. 210. 05011 https://doi.org/10.1051/e3sconf/202021005011. 
9. Marmorshtein A., Petrov V., Lukyanov A., Lukyanova A., Kovalenko A. Impact of the south Russia weather conditions on the fruitfulness coefficients of domestic breeding grape varieties. V sbornike: E3S Web of Conferences. Ser. I"International Scientific and Practical Conference «Fundamental and Applied Research in Biology and Agriculture: Current Issues, Achievements and Innovations», FARBA 2021» 2021.

10. Popovic T., Mijovic S., Raicevic D., Pajovic R. Impact of climate factors on yield and quality of vine variety Cabernet Sauvignon in Podgorica wine growing region // Agriculture and Forestry. 2016. Vol. 62 (2). P. 275-282. http://dx.doi.org/10.17707/AgricultForest.62.2.24.

11. Boselli M., Tempesta G., Fiorilo M., Brandi M. Resistance and resilience to changing climate of Tuscany and Valpolicella wine grape growing regions in Italy // BIO Web Conf. 2016. Vol. 7. 01012. https://doi.org/10.1051/bioconf/20160701012

12. Gavrilescu G., Bois B. Chardonnay wines climate plasticity: A worldwide geographical approach / Plasticité des vins issus de cépage Chardonnay au climat : une approche géographique à ll'échelle planétaire // BIO Web Conf. 2016. Vol. 7. 01013. https://doi.org/10.1051/bioconf/20160701013

13. Lung M-L., Pop N., Ciobanu F., Babes A., Bunea C., Lazar S.-L. Environmental Factors Influence on Quality of Wine Grape Varieties in Four Different Areas of Culture // Bul. Univ. Agr. Sci. and Vet. Med. Cluj-Napoca. Hort. 2012. Vol. 69 (1). P. 219-227.

14. Kisil' M.F., Vladov P.G. Formirovanie produktivnogo potenciala vinograda v zavisimosti ot ekologicheskih uslovij // Vinodelie i vinogradarstvo. 2010. № 1. S. 30-31.

15. Naumova L.G., Novikova L.Yu. Analiz tendencij izmeneniya urozhajnosti sortov vinograda kollekcii VNIIViV im. Ya.I. Potapenko // Vinodelie i vinogradarstvo. 2014. № 5. S. 44-49.

16. Koyama K., Ikeda H., Poudel P.R., Goto-Yamamoto N. Light quality affects flavonoid biosynthesis in young berries of Cabernet Sauvignon grape // Phytochemistry. 2012. Vol. 78. P. 54-64 (2012) http://doi.org/10.1016/j.phytochem.2012.02.026

17. Anapskaya ampelograficheskaya kollekciya (biologicheskie rastitel'nye resursy) / Egorov E.A., Il'ina I.A., Petrov V.S. [i dr.]. Krasnodar, 2018. 194 s.

18. Strategiya uluchsheniya sortimenta vinograda dlya kachestvennogo vinodeliya / V.S. Petrov [i dr.] // Dostizheniya, problemy i perspektivy razvitiya otechestvennoj vinogradovinodel'cheskoj otrasli na sovremennom etape: materialy Mezhdunarodnoj nauch.-prakt. konf. Rossijskaya akademiya sel'skohozyajstvennyh nauk, FGBNU Vserossijskij nauchno-issledovatel'skij institut vinogradarstva i vinodeliya imeni Ya.I. Potapenko Rossijskoj akademii sel'skohozyajstvennyh nauk (GNU VNIIViV Rossel'hozakademii). 2013. S. 113-119.

19. Terry D.B., Kurtural S.K. Achieving Vine Balance of Syrah with Mechanical Canopy Management and Regulated Deficit Irrigation // Am. J. Enol. Vitic. 2011. Vol. 62 (4). P. 426-437 http://doi.org/10.5344/ajev.2011.11022

20. Martinez Toda F., Balda P. Reducing the $\mathrm{pH}$ of wine by increasing grape sunlight exposure: a method to mitigate the effects of climate warming // Vitis. 2014. Vol. 53(1). P. 17-20. https://doi.org/10.5073/vitis.2014.53.17-20

21. Petrov V.S., Alejnikova G.Yu., Marmorshtejn A.A. Agroekologicheskoe zonirovanie territorii dlya optimizacii razmeshcheniya sortov, ustojchivogo vinogradarstva i kachestvennogo vinodeliya: monografiya. Krasnodar: FGBNU SKFNCSVV, 2020. 138 s. 